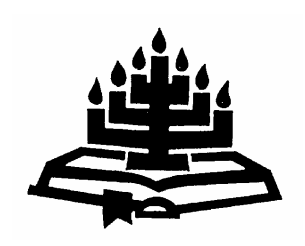

\title{
Die rol van Godskennis in die ontmoetingsgebeure met God in die prediking
}

\author{
H.J.C. (Hennie) Pieterse \\ Departement Praktiese Teologie \\ Universiteit van Pretoria \\ PRETORIA \\ E-pos: pietehjc@absamail.co.za
}

\begin{abstract}
The role of knowledge of God in the encounter with God in preaching

In an era of modernism and postmodernism homiletics is confronted with the problem of reference to God in preaching. According to current epistemologies we cannot have any knowledge of God that can be defended as true knowledge in the forum of academic discourse. In reformed theological theory, according to Calvin, knowledge of God, knowledge of ourselves in the eyes of God, as well as of salvation in Christ is a sine qua non for an encounter with God in preaching in the context of the worship service. This article proceeds from the theological stance that we can find this knowledge only in Scripture through the work of the Spirit. Recent empirical research in Reformed Churches in the Netherlands has shown that church members attend the services expecting to have an encounter with God. The sermon in this expected encounter is still very important for them. A homiletical theory that works with these presuppositions (knowledge of God) has a further problem. There is a growing Biblical illiteracy in Western societies - also in South Africa. As an answer to this problem the author proposes that the teaching sermon along the lines of Calvin's position on preaching should get more attention in our day.
\end{abstract}




\section{Opsomming}

\section{Die rol van Godskennis in die ontmoetingsgebeure met God in die prediking}

Die homiletiek in ons tyd van modernisme en postmodernisme word gekonfronteer met ' $n$ probleem van verwysing na God in die prediking. Volgens die gangbare epistemologieë kan ons nie kennis van God verkry wat as ware kennis in die akademiese forum verdedig kan word nie. In die gereformeerde teologie, volgens Calvyn, is kennis van God, van onsself in die oë van God, asook kennis van die heil in Christus, 'n sine qua non vir 'n ontmoeting met God in die prediking in die konteks van die erediens. Hierdie artikel vertrek vanuit die teologiese standpunt dat ons hierdie kennis slegs in die Skrif deur die werk van die Gees kan vind. Onlangse empiriese ondersoek in reformatoriese kerke in Nederland het aangetoon dat kerklidmate steeds kerk toe gaan met die verwagting om 'n ontmoeting met God te kan hê. Vir hulle speel die preek 'n belangrike rol in hierdie ontmoeting. 'n Homiletiese teorie wat met hierdie vooronderstellings werk het egter 'n verdere probleem: daar is 'n groeiende ongeletterdheid in die Skrif in Westerse gemeenskappe - ook in Suid-Afrika. As 'n antwoord op hierdie probleem, stel die outeur voor dat die preek as onderrig, volgens Calvyn se visie op die prediking, meer aandag in ons huidige opset moet kry.

\section{Inleiding}

In 'n boek oor die homiletiek skryf Johan Cilliers oor die Woord van God wat sentraal staan in die prediking van die evangelie (Cilliers, 2004). Hy vertrek vanuit die basiese reformatoriese beginsel van die viva vox evangelii. In 'n vernuwende styl skryf hy oor die eenstemmigheid op die kansel as die geheim van die prediking: 'n gebeure in die preek wanneer die teenwoordige God praat, wanneer die Bybelteks praat, wanneer die gemeente praat en wanneer die prediker praat - 'n samevloeiing van stemme wat een-stemmig die evangelie van Jesus Christus laat klink. Wat 'n vreugde is dit nie as daar weer 'n nuwe boek oor die homiletiek in Afrikaans uit gereformeerde kring die lig sien nie! Oor die speerpunt van Cilliers se homiletiese teologie (woorde van God wat geskied in die prediking van die evangelie van Jesus Christus) het prof. Cassie Venter en die skrywer van hierdie artikel nog altyd hartlik saamgestem (vgl. onder andere Venter, 1992a; 2001a; 2001b; 2003; asook Pieterse, 1990). Prof. Venter is 'n mens met 'n oop en wetenskaplike gemoed. In die vernuwende ontwikkelinge in die Praktiese Teologie van die laaste dekades, het hy saamgedink - 
altyd vanuit 'n stewige Skriftuurlike grondslag (vgl. bv. Venter, 1992b; 1996a; 1996b). Dit is daarom 'n besondere voorreg vir my om hierdie artikel oor die prediking by die geleentheid van sy emeritaat te kan lewer.

Daar is egter tans ten opsigte van die grondvrae in die homiletiek ' $n$ probleem wanneer 'n mens skryf oor die Woord van God, of God se woord in mensetaal, of woorde oor God wat in die prediking van die evangelie geskied. Cilliers skryf oor die stem van God in die prediking, maar gaan nie grondig in op die heersende denke oor die moontlikheid om oor God te praat vanuit die gesigspunt van die heersende akademiese diskoers nie. Die erfenis van die Verligting, van die Kantiaanse epistemologie wat bykans alle dissiplines aan universiteite deurdring het, plaas ons vertrekpunt, dat Skrifkennis ware kennis is, onder druk. Ook die heersende postmoderne filosofie meen ondanks haar nuwe belangstelling in metafore, simbole en spiritualiteit, eintlik ook dat ons niks van God kan weet nie (vgl. Pieterse, 2005; Lyotard, 1990 oor die funksie van taal; Lose, 2003:19; Immink, 2003:46). Daar heers 'n geestesklimaat in ons Westerse denke ('n denke waarvan die lede van die Afrikaanse kerke tradisioneel deel is) waarin dit moeilik word om van 'n sprekende God extra nos te praat. Daar het 'n sterk antroposentriese gees ontstaan waarin die mens die maatstaf van alles is. In die teologie word geworstel met die huidige siening van die werklikheid, naamlik dat ons eintlik, wat akademiese kennis aanbetref, niks van God kan weet nie (vgl. byvoorbeeld Carson, 1996; Houtepen, 1997; Jüngel, 1999; Dingemans, 2000). Die praktiese teologie lê 'n sterk klem op God se inisiatief in sy koms na ons toe in die openbaring van die Skrif (vgl. Firet, 1977). Die klem swaai tans na die menslike ervaring, na "... een visie op openbaring die de menslijke ervaring zozeer tot inzet neemt, dat er geen ruimte overblijft voor een eigen, onafhanklijke inbreng van Gods Geest in de communicatie van het evangelie" (Stark, 2003:227). God is vir baie mense in ons (post)moderne wetenskaplike wêreldbeeld 'n hipotetiese menslike konstruksie (vgl. Sanders, 2004:51). God sit slegs in ons verbeelding, of $\mathrm{Hy}$ is slegs ' $\mathrm{n}$ religieuse simbool. Dit is duidelik dat die prediking in hierdie denkklimaat, wat deur 'n spesifieke kennisleer en taalfilosofie geskep is, in die moeilikheid is. In die Nederduitse Gereformeerde Kerk, is daar byvoorbeeld nog verdere faktore by sommiges aan die werk, soos 'n postmoderne bevraagtekening van die gesag van die Skrif en aan die ander kant, 'n charismatisering waarin die emosies van die mens sterk funksioneer, met 'n teologiese aanpak wat swaar leun op 'n sterk evangelikaalse (ek verkies hierdie term om dié soort teologie te 
beskryf, in plaas van die Bybelse term "evangeliese"), of wat selfs op 'n Pinksterteologie leun (vgl. Schoeman \& Bisschoff, 2004:124). Dit plaas die gereformeerde prediking in die huidige denkklimaat en tydsgees verder onder druk (vgl. Du Toit et al., 2002: 14-50). In 'n opvolgartikel in my projek om hierdie probleem te behandel, sal ek argumenteer vir 'n ander benadering tot die epistemologie en 'n ander benadering in die taalfilosofie, wat wel 'n eksterne, objektiewe werklikheid buite die mens erken. So 'n denkmodel behoort ruimte te skep waarin Bybelkennis - wat deur die getuienis van die Bybelskrywers van buite ons deur God se inisiatief na ons toe kom as betroubare kennis in die akademiese forum erken behoort te word.

In hierdie artikel gaan ek teologies daarvan uit dat ons vanweë die kennis in die Skrif, kennis van God en van onsself deur Sy genadige verligting deur die Gees mag verkry (Calvijn, 1956:1-4). Hierdie kennis speel 'n belangrike rol in die prediking waarin 'n woord van God gehoor kan word as 'n aktuele woord in elke konteks. Om hierdie saak te bespreek, sal ek eerstens 'n beskrywing gee van die algemene houding en sienings van die breë bevolkingsgroep ten opsigte van Skrifkennis, as die konteks waarin ons preek; daarna volg ' $n$ bespreking van 'n teologiese teorie oor die funksionering van kennis van God en onsself - ten opsigte van die rol daarvan in 'n ontmoeting met God deur die prediking, in die konteks van die erediens; en laastens word die belangrikheid van aktuele, onderrigtende prediking in ons tyd beklemtoon.

\section{Die moderne mens en die gebrek aan Skrifkennis}

\subsection{Veranderende lewensbeskouings}

Ten grondslag van die sterk veranderings in die lewensbeskouings van die mense vandag teenoor ongeveer vyftig jaar gelede, is die veranderinge wat as orality shifts bekend staan. Orality shifts is 'n begrip wat deur Walter Ontong gemunt is (vgl. Quicke, 2003:74-81). In Suid-Afrika skryf en praat Johan Rossouw, 'n jong filosoof, ook oor hierdie verskuiwing in die wyse waarop daar gekommunikeer word. Hy praat van 'n tyd toe skrif uitgevind is as die logosfeer, die uitvinding van die drukkuns as die grafosfeer en die ontwikkeling van die oudiovisuele media as die videosfeer (lesing by die Universiteit van Pretoria in Februarie 2005). Met ontwikkeling van die skryfkuns deur die Sumeriërs ongeveer 3500 v.C. het spraak verskuif vanuit 'n orale gehoor-wêreld na die sensoriese wêreld van sien (die logosfeer). Woorde kon nou nie net gehoor word nie, maar ook gesien word (Du Plessis, 2004:14). Met die koms van die 
boekdrukkuns, kon met die massas gekommunikeer word en die mens hoef nie meer alles te onthou nie, maar inligting kon in boeke, woordeboeke en ensiklopedieë versamel word (die grafosfeer). Om te kan skryf het 'n onontbeerlike hulpmiddel in kommunikasie geword. Met die meer onlangse ontwikkeling van die elektroniese media, is 'n tydperk ingelui wat die mens se wyse van dink en kommunikeer ingrypend verander het (die videosfeer). Televisie vertoon byvoorbeeld beelde, nie konsepte nie. Inligting word oorgedra in grepe of indrukke, eerder as in opeenvolgende orde. Advertensies kom byvoorbeeld met vyftig beelde in dertig sekondes. Die mens se konsentrasiespan is korter en ons luister meer passief (Du Plessis, 2004:18). Die bevinding van Kruger (2002:185-186), naamlik dat hoorders van die preek by lidmate van Afrikaanse kerke in die reformatoriese tradisie sukkel om te konsentreer as preke volgens hulle langdradig is, klop met hierdie teoretiese siening oor die videosfeer. As 'n visuele medium is die beeld en die grafika die hart van kommunikasie en nie die woorde wat gespreek word nie.

In die logosfeer was die kerk met haar prediking en dogma belangrik as houers van die maatskaplike sakrale, volgens Rossouw. In die grafosfeer was die belangrikste die professore en doktore met kennis as die belangrikste saak. Alhoewel die kerk met sy prediking voortbestaan het, het haar oorheersende posisie in hierdie tydvak begin kwyn. In die videosfeer is die elektroniese media die houer van die maatskaplike sakrale en inligting is die allerbelangrikste saak. Dit het die prediking van die kerk verder onder druk geplaas binne die moderne kommunikasiestyl. Die normale invloedsmiddel, volgens Rossouw, lyk soos volg: Logosfeer (die preek), grafosfeer (die publikasie) en videosfeer (die verskyning as beelde op die elektroniese media). Die dinge wat tans gesag dra is dít wat op televisie of die internet gesien word en die opinie van individue word as geldig beskou - 'n siening wat ook uitgedruk word deur die postmoderne gees: alles is relatief en elke persoon se idee van waarheid is aanvaarbaar. Die videosfeer van ons tyd laat mense passief kyk en minder lees. Dit het 'n belangrike invloed op die lees van die Bybel en Skrifkennis verminder dus by baie mense.

'n Nuwe generasie jongmense en jong ouers van gesinne met 'n nuwe houding en lewensuitkyk sit deesdae in ons kerke wanneer ons preek. In die VSA noem Barna (2001:12) dié generasie wat tussen 1965-1983 gebore is Baby Busters. Carson (1996:45) vermeld dat Baby Busters die generasie is wat tussen 1960-1975 gebore is. Die effense verskil tussen die datums is geen probleem nie, omdat dit om generasies gaan wat in 'n sekere tydperk min of meer dieselfde sienings verteenwoordig. Graeme Codrington noem 
in sy ondersoek in Suid-Afrika hierdie generasie Generation $X$ (Codrington, 1998). Vanweë ons isolasie deur die boikot van die tagtiger- tot met die helfte van die negentigerjare van die vorige eeu, is hierdie generasie vir Afrikaanssprekendes gedefinieer as die generasie wat tussen 1975-1990 gebore is. Alhoewel Generation X dus 'n latere datum het, vertoon hulle dieselfde soort sienings as hul Amerikaanse eweknieë (vgl. Meyer, 2002:45-56). Vir die doel van hierdie artikel gaan dit veral oor hul pragmatisme. Hulle vra nie of iets waar is nie, maar of dit werk. Waarheid is relatief en daarom hang hulle ' $n$ individuele moraliteit aan. Die fokus is weg van die objektiewe en is voluit gerig op die subjek - op die mens self met sy vooronderstellings, gevoel, geloof en eie soort spiritualiteit (vgl. Meyer, 2002:51).

It is said that baby busters do not want to be lectured; they expect to be entertained. They prefer videos to books; many of them have not learned to think in a linear fashion; they put more store than they recognize in mere impressions ... their emotions so rule their heads that very frequently no amount of argumentation is adequate (Carson, 1996:45).

Geen wonder dat daar so 'n groot klem in baie kerke gelê word op die emosie en ervaring van die mens nie en al minder op kennis van ons gereformeerde leer as die interpretasie van die onderwysing van die Skrif aan die bod kom. Skriftuurlike kennis van God en onsself, as 'n basis vir die prediking waarin 'n sola gratia-ervaring van 'n ontmoeting met God as regverdigmakende God deur die geloof alleen gebeur, is besig om by baie moderne hoorders van die skerms te verdwyn. Barnard (2004:72) bevind in 'n empiriese ondersoek dat alhoewel die predikante in die Ring van die Paarl in die Nederduitse Gereformeerde Kerk (gemeentelike styl) voorkeur gee aan 'n kopspiritualiteit as 'n beskrywing van die kennis van God en mens in die lig van die Skrif (44\% teenoor $26 \%$ vir hartspiritualteit en $17,5 \%$ vir mistiekspiritualiteit), slegs $21 \%$ van die lidmate voel vir 'n kopspiritualiteit, terwyl $32 \%$ 'n hartspiritualiteit en $28 \%$ 'n mistiekspiritualiteit verkies. Onder die lidmate speel die emosionele en ervaringsgodsdiens dus ' $n$ veel groter rol as die meer gereformeerde bedieningstyl wat die predikante in die gemeentes handhaaf.

Sommige mense in Suid Afika redeneer dat die postmoderne paradigma die vorige (moderne) paradigma totaal vervang het. Ongelukkig is dit nie so nie - veral in Suid-Afrika skuif premoderne, moderne en postmoderne denke voortdurend oormekaar. In die teologie en die breë samelewing kan ou paradigmas bly 
voortbestaan. Die reformatoriese paradigma leef byvoorbeeld steeds voort in Protestantse konfessionalisme en dié van die Verligting in die liberale teologie, soos byvoorbeeld in die vrysinnigheid van die Nuwe Hervormers te sien is (vgl. Bosch, 1991:186). Die geslote wêreldbeeld, wat 'n erfenis is van die modernisme se wetenskaplike wêreldbeeld, leef in baie Afrikaanse kerklede voort. Volgens hierdie denke is daar nie 'n goddelike werklikheid buite die mens nie. Ek het 'n grondige empiriese ondersoek gedoen met 'n steekproef van lidmate van die Nederduitse Gereformeerde Kerk in die Oostelike voorstede van Pretoria (vgl. Pieterse, 1997) voortbouend op C.J. Alant se ondersoeke en sy hipotese dat die hoër sosio-ekonomiese groep onder hierdie kerklidmate in Pretoria die tendense van sekularisasie en 'n geslote wêreldbeeld begin vertoon in hul denke oor God (Alant, 1972). Die 1997-ondersoek dui daarop dat tot $40 \%$ van die boonste sosio-ekonomiese groep 'n geslote wêreldbeeld begin handhaaf en God alleen binnewêrelds (immanent) begin sien (Pieterse, 1997:186-188). In so 'n situasie vervaag die werklikheid van God wat in die Skrifteks exra nos ons aanspreek.

\subsection{Kwynende Skrifkennis}

Die veranderende lewensbeskouings en die tydsgees, soos hierbo kortliks geskets, het ' $n$ invloed op die lees van die Bybel en die Skrifkennis van selfs kerklidmate. Die gesag van die Skrif word bevraagteken in die diskussie in teologiese kringe (vgl. Cilliers, 2004:15; Du Toit et al., 2002:14). Lidmate twyfel of die Skrif en die evangelie nog betroubaar is in die lig van hierdie diskussies wat ook in die koerante gevoer word. ' $n$ Uitvloeisel van hierdie tydsgees is die verminderde lees van die Bybel.

Daar is empiriese bewyse dat daar 'n stygende ongeletterdheid ten opsigte van die Bybel is. In die VSA berig Carson (1996:42) soos volg:

In 1950 the Gallup organization asked the question, 'Did you receive any religious instruction in your youth?' Only 6 percent of Americans answered negatively. When the same question was put to people in 1989, the figure has risen to 38 percent.

In Suid-Afrika is 'n longitudinale, kwantitatiewe ondersoek gedoen na die godsdienstige, politieke en sosiale vorming van 'n groot aantal tieners in Graad 11 in skole in Pretoria en Johannesburg en die invloed daarvan op hul sieninge van God, Jesus, die kerk, Vigs, menseregte, ensovoorts. Op die vraag of hierdie leerders die Bybel 
lees, het die tieners van die Afrikaanse skole in die 1996-opname soos volg geantwoord:

Gereeld: $50,2 \%$. Nou en dan: $26,7 \%$. Selde: $19,1 \%$. Nooit: $4,0 \%$.

Op dieselfde vraag het die Afrikaanse leerders van die opname in 2001 in dieselfde skole en ook in Graad 11 soos volg geantwoord:

Gereeld: $45,1 \%$. Nou en dan: $31,6 \%$. Selde: $16,7 \%$. Nooit: $6,5 \%$.

Hierdie persentasies toon 'n effens dalende tendens in die lees van die Bybel. Net die helfte en, vyf jaar later, minder as die helfte jongmense lees die Bybel gereeld. Dit dui op kwynende Skrifkennis (vgl. Van der Ven, Dreyer \& Pieterse, 2004).

Die vraag is dus of die gereformeerde insig - dat kennis van God en van onsself in ons toestand voor God 'n rol speel in die ontmoetingsgebeure met God in die prediking - met hierdie tendens van verminderde Skrifkennis, nie onder druk kom nie. Godskennis is kennis wat voortvloei uit ons vertroue op God en gehoorsaamheid aan God. Dit is geloof wat op soek is na verstaan. Ons kan God nie deurgrond nie, maar omdat ons op Hom vertrou, is daar 'n strewe na steeds dieper insig en begrip. Hierin speel die prediking 'n belangrike rol. Deur die prediking van die Woord en die werk van die Gees ervaar ons hierdie kennis as eksistensiële kennis - die heilswerk van Christus het ook pro me geskied. Ons verstaan die Skrif se boodskap dus as Christus alleen, genade alleen en geloof alleen as die heilsweg in ons ontmoeting met God in die prediking, deur die werk van die Gees.

\section{Kennis van God en kennis van onsself in die lig van die Skrif}

Spangenberg (1998:28, 30-31) beskryf die Reformatoriese Skrifbeskouing en sy eksegetiese metode as voor-krities. Myns insiens, is Calvyn se teologiese insig, gesien vanuit die perspektief van die gereformeerde homiletiek, egter ook vir ons moderne tyd geldig in die boodskap van die Skrif. Calvyn se teologiese insig handel oor die kennis van God en die kennis van ons eie toestand voor God in die lig van die Skrif, asook oor die verlossingsboodskap van die evangelie van Jesus Christus (vgl. ook Van der Kooi, 2002). Of die eksegese nou ook al 'n Woord van God uit die teks haal (Reformasie), of God se woord in mensetaal oorsit (histories-kritiese metode), of woorde oor God spreek (moderne literatuurwetenskap- 
like benadering) die betekenis van die teks sal van God se woorde, handelinge en beloftes getuig, omdat ons bely dat die Gees daarin werksaam was en is. Deur die Gees sal God se woord deur hermeneuse en homilese 'n preek word waarin oor God gepraat word op so 'n wyse dat die gelowige gemeente Hom in daardie gebeure kan ontmoet. Die ontmoetingsgebeure word dus bewerk deur die Gees wat teks en hoorder verbind en die heil in Christus toepas in die harte van die gelowiges. Ciska Stark (2005:444, 446, 467) se empiriese ondersoek in Nederland onder lidmate van De Gereformeerde Kerken in Nederland en lidmate van De Nederlandse Hervormde Kerk van verskillende modaliteite, toon dat die lidmate steeds ' $n$ verwagting het om God in die erediens en die preek te ontmoet - en dat dit gebeur. Stark (2005:205) het ook verder in haar ondersoek bevind dat die verband tussen Woord en Gees in die Protestantse tradisie in die gebeure van die preek onlosmaaklik is.

Calvyn stel dat hoewel God hom in die skepping en geskiedenis openbaar, ons slegs 'n vae kennis daardeur van Hom verkry (Calvijn, 1956:37). Ware kennis van God kan ons slegs verkry deur die lees van die Skrif onder die verligting van die Heilige Gees. Hy gebruik daarvoor die metafoor van die bril. Ons het die "bril" van die Skrif onder die verligting van die Gees nodig om tot geloofskennis van die ware God te kan kom (Calvijn, 1956:37). Die beweging is van God af na ons toe in Sy openbaring in die Skrif, wanneer Hy deur sy Gees die lig laat skyn oor die Here Jesus Christus. Van die mens se kant gesien, is die begin van hierdie kennis van God in die Skrifopenbaring, by die Gees wat ons Christus laat leer ken in wie ons die Vader ontdek (vgl. Baars, 2004:673). Oor sy wese het God ons min geopenbaar (Calvijn, 1956:6-7). Om spekulasie te voorkom, moet ons dus die Skrif as bron van kennis oor die God van die Bybel gebruik.

As ons na die aard van die Godskennis in die Skrif vra, gaan dit oor hóé God teenoor ons is (Baars, 2004:670). Hierdie kennis is by Calvyn soteriologies van aard (vgl. Baars, 2004:670-673; Van der Kooi, 2002:43). Wanneer Calvyn dus van die doctrina praat wat die blye boodskap van die prediking moet wees, bedoel hy die evangelie van Jesus Christus (Pieterse, 1990:90-94). Ons Godskennis is dus praktiese kennis waarin ons in die geloofsomgang met God hom ervaar as by ons. Baars (2004:673) vertaal Calvyn se Latyn soos volg:

... de praktische kennis waardoor '... het vrome hart God in Zijn onmiddellijke tegenwoordigheid ontdekt en Hem bijna aanraakt, 
wanneer het ondervindt dat het levend gemaakt, verlicht, zalig gemaakt, gerechtvaardigd en geheiligd wordt.

In die Latyn lees dit soos volg (Baum, Cunitz, Reuss, 1870:705 r. 79):

“... pius animus Deum praesentissimum conspicit et paene attrectat, ubi se vivificari, illuminari, salvari, iustificari ac sanctificari sensit" (vgl. Baars, 2004:673).

Kennis van God deur die boodskap van die Skrif in die prediking is dus gerig op 'n ontmoeting met God in die erediens.

Ons doen (eers) kennis op van God in die Skrif en ervaar dan die belewenis van ' $n$ geloofsontmoeting met Hom. Daar is ' $n$ interaksie tussen Skrif en ervaring: Calvyn praat van twee leermeesteresse (magistrae) of twee bronne (fontes) wat ons kennis van die drieenige God verskaf: die Skrif en die ervaring (Baars, 2004:674). Hiermee is nie bedoel dat daar naas die Skrif nog 'n bron van Godskennis is nie. Aan die sola Scriptura is die ervaring van die geloof onderworpe en is ook afhanklik daarvan. Die Skrifkennis van die drie-enige God word in die geloofsontmoeting in die preekgebeure 'n eksistensiële kennis. Daar is 'n interaksionele proses aan die gang. Volgens Baars (2004:674) ontstaan die eksistensiële kennis:

... door de inwerking van Woord en Geest op het hart en daarom richt zij zich op het Woord en weet zich daaraan onderhorig. Tegelijkertijd leert zij door de ervaring van het geloof dat de drie-enige God werkelijk zo is, zoals Hij zich in Zijn Woord openbaart.

Vir die voortgang van 'n dinamiese geloofsleer gebou op die Skrif, is hierdie interaktiewe proses van Skrifverkondiging en ervaring van die geloofsontmoeting met God noodsaaklik (vgl. Sanders, 2004:5557). Skrifkennis van God en onsself en God se heilsplan in Christus - geloofsleer - is dus noodsaaklik vir effektiewe prediking. In 'n tyd waar mense (ook kerklidmate) se Skrifkennis skraal word, word onderrigtende prediking al hoe belangriker.

\section{Prediking as onderrig}

In die lig van die vermindering van geletterheid in die Bybel en die groeiende gebrek aan kennis van die Skrif, is dit nodsaaklik dat ons meer klem op onderrigtende prediking sal lê. In die laaste dekades het die homiletiek goeie vordering gemaak met die besef dat kommunikasie belangrik is en dat die preekgebeure ten diepste 'n 
dialoog is tussen prediker en hoorder. Die preekgebeure is ook 'n dialoog tussen die boodskap van die teks en die hoorder deur die verbindingswerk van die Gees, dit wil sê deur nuwe insigte in kommunikasie en die hermeneutiek (vgl. Pieterse, 1988). Die wending na die hoorder was 'n wins wat ons help om die boodskap in die situasie en in die beleweniswêreld van die hoorder toe te pas (vgl. Van der Laan, 1989). In die lig van die huidige situasie van die hoorders in die VSA, in Nederland en in Suid-Afrika ten opsigte van Skrifkennis, blyk egter dat die prediking as onderrig, of didaktiese prediking, verwaarloos is (Immink, 2004:105).

Calvyn en die ander Reformatore het klem gelê op die lerende prediking (didache). In Calvyn se woorde: "Want het enige middel waardoor de mensen tot de zaligheid kunnen komen, is onderwezen worden in de leer van het evangelie" (Moehn, 1996:256). Tog het hulle nie die belang van die kerugma onderspeel nie. Calvyn gebruik twee metafore in verband met die prediking: die skool en die ambassadeur (vgl. Immink, 2004:106; Parker, 1992). Die prediker as ambassadeur van Christus, verkondig die evangelie as kerugma. Vir die magister in die skoolmetafoor is die prediking onderrig. Albei tipes prediking is instrumente van die Gees, wat beteken dat die boodskap van verlossing teenwoordig en effektief in die prediking is. Onderrigtende prediking is dus nie dorre leerredes en slegs kognitief nie, maar is 'n uitleg van die Skrif op so 'n wyse dat die Bybelse boodskap verstaan word in sy bevrydende krag en sy implikasies vir die lewe van die gelowige. Prediking as onderrig is dus ook aktuele prediking.

Didaktiese prediking word deur Stark (2005:333) soos volg omskryf:

Het gaat er hoe dan ook om dat de inhoud van de Schrift duidelijk wordt en dat maakt dit preektype tot een belangrijke hulp voor de gemeente bij het eigen Schriftverstaan. De vooronderstelling dat geloof met een leerproces te maken heeft en dat de Schrift een essentieel 'leermiddel' van Godswege is, kan maken dat de hoorders bij zichzelf de ruimte in hun geloofsleven toelaten om permanent te leren en zich te ontwikkelen in hun geloof.

Didaktiese prediking is 'n verklaring van die Skrif en 'n aanwysing uit die Skrif dat Jesus die Saligmaker is waarin die verstand, maar sekerlik ook die hart en siel, ten volle by betrokke is. Dit gaan om die inwyding in die geheimenis van die geloof, maar ook om die alledaagse geloofsbestaan (Stark, 2005:239). Stark het sestien preke ondersoek waarin daar die volgende tipes teenwoordig was: tekssentriese kerugmatiese, didaktiese en parakletiese preke, asook 
toepassingsentriese kerugmatiese, didaktiese en parakletiese preke. Van die sestien preke wat sy ondersoek het, het die hoorders in hul evaluering van die preke, vier preke aangetoon wat die meeste gewaardeer is. Daarvan was drie didaktiese preke (Stark, 2005:448). In haar bevindinge aan die einde van hierdie proefskrif stel sy die volgende: "Religieuze ervaring is voor wat betreft de protestantse preek sterk verbonden met een propositionele inhoud" (Stark, 2005:453). In die kommunikasieklimaat van ons tyd is dit baie belangrik om hierby matig gebruik te maak van 'n PowerPoint met visuele beelde.

\section{Konklusie}

In die gereformeerde teologie is die rol van Godskennis wat gebou is op Skrifkennis uiters belangrik in die prediking met die oog op 'n ontmoetingsgebeure met God. In hierdie ontmoetingsgebeure word die heil in Christus ervaar en toegeëien. Dit blyk egter dat die Afrikaanssprekendes, en ook lidmate van die kerk se kennis van die Skrif aan die kwyn is. Hierdie kwynende Skrifkennis impliseer dat ook hul kennis van wie God is, wat ons toestand as sondaarmense voor Hom is en dat die weg tot heil in Christus is, aan die kwyn is. Onderrigtende prediking sal daarom al meer moet fokus op aktuele, dinamiese prediking waarin die hoorders die heil in Christus kan ervaar en aanvaar.

\section{Geraadpleegde bronne}

ALANT, C.J. 1972. The relevance of sosio-economic groups in the analysis of the Nederduitse Gereformeerde Kerk in South Africa. Social Compass, 19(1):21-28.

BAARS, A. 2004. Om Gods verhevenheid en Zijn nabijheid: De Drie-eenheid by Calvijn. Kampen: Kok.

BARNA, G. 2001. Real teens. California: Regal Press.

BARNARD, P.H. 2004. 'n Prakties-teologiese ondersoek na spiritualiteitstipes in eredienste in die Ring van die Paarl. Pretoria: Universiteit van Pretoria. (M.A. Teologie-verhandeling.)

BAUM,G., CUNITZ, E. \& REUSS, E., eds.,1863-1900. Ioannis Calvini Opera Quae Supersunt Omnia I-LIX. Brunsvigae: Berolini.

BOSCH, D.J. 1991. Transforming mission: Paradigm shifts in theology of mission. Maryknoll: Orbis Books.

CALVIJN, J. 1956. Institutie. Deel I. Derde Druk. Delft: Meinema.

CARSON, D.A. 1996. The gagging of God: Christianity confronts pluralism. Grand Rapids: Zondervan.

CILLIERS, J. 2004. Die lewende stem van die evangelie. Stellenbosch: Sun Press.

CODRINGTON, G. 1998. Generation X: Who, what, why and where to? www.youth.co.za/genxthesis.ch.1.htm [2 March 2005]. 
DINGEMANS, G.D.J. 2000. De stem van de roepende. Kampen: Kok.

DU PLESSIS, I. 2004. Multisensoriese liturgie. Pretoria: Universiteit van Pretoria. (M.A. Teologie-verhandeling.)

DU TOIT, F., HOFMEYR, H., STRAUSS, P. \& VAN DER MERWE, J. 2002. Moeisame pad na vernuwing. Bloemfontein: Barnabas.

FIRET, J. 1977. Het agogisch moment in het pastoraal optreden. Kampen: Kok.

HOUTEPEN, A. 1997. God een open vraag: Theologische perspectieven in een cultuur van agnosme. Zoetermeer: Boekencentrum.

IMMINK, F.G. 2003. In God geloven: Een praktisch-theologiese reconstructie. Zoetermeer: Meinema.

IMMINK, F.G. 2004. Homiletics: The current debate. International Journal of Practical Theology, 8:89-121.

JÜNGEL, E. 1999. Das Evangelium von der Rechtfertigung des gottlosen als Zentrum des christlichen Glaubens. Tübingen: Mohr Siebeck.

KRUGER, F.P. 2002. Prediking en gesindheidsverandering: 'n Praktiesteologiese studie in die lig van Hebreërs. Potchefstroom: $\mathrm{PU}$ vir $\mathrm{CHO}$. (Th.M.-verhandeling.)

LOSE, D.J. 2003. Confessing Jesus Christ: Preaching in a postmodern world. Grand Rapids: Eerdmans.

LYOTARD, J.F. 1990. Heidegger en 'de joden'. Kampen: Kok.

MEYER, L.M. 2002. Gereformeerde liturgie onder 18- tot 15-jarige Afrikaanssprekendes in die lig van die huidige kultuursituasie. Potchefstroom: PU vir CHO. (Th.M.-verhandeling.)

MOEHN, W.H. Th. 1996. God roept ons tot Zijn dienst: Een homiletisch onderzoek naar de verhouding tussen God en hoorder in Calvijn's preken over Handelingen 4:1-6:7. Kampen: Kok.

PARKER, T.H.L. 1992. Calvin's preaching. Louisville: Westminster/John Knox.

PIETERSE, H.J.C. 1988. Die Woord in die werklikheid. Pretoria: NG Kerkboekhandel.

PIETERSE, H.J.C. 1990. Prediking as ontmoetingsgebeure met God - by Calvyn. Praktiese Teologie in Suid-Afrika, 5(2):88-96.

PIETERSE, H.J.C. 1997. Immanentistic beliefs in God: Modern pantheism. (In Dekker, G., Luidens, D.A. \& Rice, R.R. Rethinking secularization: Reformed reactions to modernity. Lanham/New York/London: University Press of America. p. 177-199.)

PIETERSE, H.J.C. 2005. Hoe kom God aan die woord in die prediking? Die probleemstelling. Praktiese Teologie in Suid-Afrika, (in proses van publikasie).

QUICKE, M.J. 2003. 360 degree preaching: Hearing, speaking and living the word. Grand Rapids: Baker Academic.

SANDERS, C. 2004. Reiken naar God: Over de mogelijkheid en onmogelijkheid van godskennis. Kampen: Kok.

SCHOEMAN, K. \& BISSCHOFF, J. 2004. Kerkspieël. Verslag van die sewende wetenskaplike opname van die Nederduitse Gereformeerde Kerk in Maart 2004 in opdrag van die Algemene Sinode. Pretoria: NG Kerkuitgewers.

SPANGENBERG, I. 1998. Perspektiewe op die Bybel. Pretoria: Van Schaik.

STARK, C. 2003. Ontferming in prediking en pastoraat (In Lanser, A., Van Nijen, J., Stark, C. \& Stoppels, S., reds. De kunst van de ontfermen: Studies voor Gerben Heitink. Kampen: Kok. p. 221-238.)

STARK, C. 2005. Proeven van de preek: Een praktisch-theologische onderzoek naar de preek als Woord van God. Zoetermeer: Boekencentrum. 
VAN DER KOOI, C. 2002. Als in een Spiegel: Godskennis bij Calvijn en Barth: Een tweeluik. Kampen: Kok.

VAN DER LAAN, J.H. 1989. Ernst Lange en die prediking. Kampen: Kok.

VAN DER VEN, J.A., DREYER, J.S. \& PIETERSE, H.J.C. 2004. Is there a God of human rights? The complex relationship between human rights and religion: A South African case. Leiden/Boston: Brill.

VENTER, C.J.H. 1992a. Prakties-teologiese grondslae van die prediking. Praktiese Teologie in Suid-Afrika, 7(1):1-16.

VENTER, C.J.H. 1992b. Diakonologie en rasionaliteit - 'n verkenning. In die Skriflig, 26 (1):181-202.

VENTER, C.J.H. 1996a. Die Woord in die werklikheid: Wetenskapsteoretiese perspektiewe op Diakonologie. In die Skriflig, 29(1 \& 2):181-202.

VENTER, C.J.H. 1996b. Uitkringende liefdesbetoon. Pretoria: RGN.

VENTER, C.J.H. 2001a. Verklarende prediking: Basisteoretiese elemente uit Hebreërs. In die Skriflig, 35(3):373-388.

VENTER, C.J.H. 2001b. Verklarende (expository) prediking - 'n herevaluering. In die Skriflig, 35(4):513-535.

VENTER, C.J.H. 2003. Die prediking van hoop aan getraumatiseerdes in die huisgesin van God. In die Skriflig, 37(1):27-50.

\section{Kernbegrippe:}

Calvyn: kennis van God

groeiende ongeletterdheid van die Skrif

ontmoeting met God in die prediking

prediking as onderrig

\section{Key concepts:}

Calvin: knowledge of God

encounter with God in preaching

growing illiteracy of Scripture

preaching as teaching 